\title{
Electrochemical Characterisation of Bovine Serum Albumin Adsorption on Phenolic- Coated Nickel-Titanium
}

\author{
Athanasios Chatzitakis* and Simon M. Longela \\ Centre for Materials Science and Nanotechnology, Department of Chemistry, University of Oslo, FERMiO, Gaustadalleen 21, NO - \\ 0349 Oslo, Norway.
}

Received 29 November 2018; Accepted 28 May 2019

\begin{abstract}
Understanding molecular interactions at the solid-liquid interface is essential to the development of biomaterials intended to function in the physiologic environment. Superelastic nickel-titanium, widely used for biomaterials applications, is here coated with two different phenolic compounds: pyrogallol and tannic acid. The adsorption of bovine serum albumin protein on these phenolic-coated surfaces is assessed by electrochemical impedance spectroscopy and cyclic voltammetry to understand the behavioural kinetics of proteins in a physiological environment. Using an electrical equivalent model, we show that pyrogallol coated surfaces adsorb more proteins than the native and the tannic acid-treated surfaces. We also show that in all cases, the amount of nickel ions leaching from the biomterial falls well withing the acceptable range for biocompatibility.
\end{abstract}

Keywords: Protein adsorption; bovine serum albumin; nickel-titanium; pyrogallol; tannic acid

\section{Introduction}

Protein adsorption is crucial in cell adhesion for tissue regeneration, even though frequent biofouling, i.e. protein accumulation, is seen as an undesirable process in some applications [1]. Therefore, protein adsorption on biomaterial surface is of great interest for bioengineering research.

The adsorption of human serum albumin (HSA) and other blood plasma proteins (Immunoglobulin $G$ and fibrinogen) have been studied in more detail than the adsorption of any other plasma proteins [2]. This is perhaps justified by the relatively large concentration of these three proteins in plasma [2]. But for in vitro studies, bovine serum albumin (BSA) is alternatively used in lieu of HSA, since its structure is similar to the HSA structure [3], with nearly the same isoelectric point [4, 5] and molecular weight [4] and also because of its low-cost.

There are a few studies available in the literature on protein adsorption on nickel-titanium (nitinol) as biomaterials [6-8]. One of these, by Shabalovskaya on polished, chemically-etched, heat treated and electropolished nickel-titanium surfaces [9], suggested that the amount of albumin adsorbed should be proportional to the nickel surface content of the alloy. In a recent literature, Lin et al. have shown that proteins form a film on the metal surface, which inhibit corrosion. The interaction of metal ions with proteins creates organometallic complexes, which may accelerate corrosion if transported away from the metal surface [10]. Despite efforts made to understand protein adsorption and achieve control over biofouling, the

*E-mail address: a.e.chatzitakis@smn.vio.no

ISSN: $1791-2377$ @ 2019 Eastern Macedonia and Thrace Institute of Technology. All rights reserved. doi:10.25103/jestr.122.01 adsorption mechanisms for a range of proteins are still not fully understood [1].

In this study, we coated nickel-titanium with two polyphenolic compounds: pyrogallol and tannic acid. These bio-inspired compounds have anti-inflammatory properties they are anti-proliferative agents, nontoxic, scavengers of reactive oxygen species and capable of forming metal ion complexes [11, 12].

Herein, BSA adsorption is investigated by different electrochemical tests in order to shed light on the interfacial phenomena that take place during biofouling. Firstly, the open circuit potential analysis (OCP), this type of measurement provides information about the 'natural' corrosion behaviour of the system undisturbed by any external voltage or current source and, therefore, in the absence of induced corrosion effects [13]. The corrosion potentials $\left(\mathrm{E}_{\mathrm{OCP}}\right)$ reflect the composite results of electrochemical reactions taking place at the surface/solution interface. Therefore, the variation in the corrosion potential, with immersion time, can be employed to study the electrochemical processes. Secondly, the electrochemical impedance spectroscopy (EIS) - EIS is a non-destructive sensitive technique enabling the detection of any changes occurring at the electrode/electrolyte interface before, during and after protein adsorption [13]. And finally, the electron transfer-initiated chemical reactions at the interface surface/protein were assessed by cyclic voltammetry (CV). These electrochemical techniques are powerful tools to investigate the absorption and charge transfer phenomena on solid/liquid interfaces. This means that they can help assess the biocompatibility of different materials intended for such applications.

Furthermore and in order to complement the electrochemical analysis, nickel ion release has also been studied for the possible diffusion and leaching of ions in the simulated physiological solution. The objectives of this 
paper were to chemically coat commercially available nitinol surfaces; to access the benefits of polyphenol coatings in terms of corrosion potential; to identify the optimal coating technique for future possible biomaterial applications; and finally to study the protein interaction on phenolic coated nickel-titanium surface and simulate its adsorption in a physiological environment.

\section{Materials and methods}

\subsection{Materials and sample preparation}

Superelastic nickel-titanium $(55.67 \% \mathrm{Ni}$ by weight, ASTM 2063) was purchased from HLMET Co. Ltd in China; in the form of $1 \mathrm{~mm}$ thick mirror surface cold rolled sheets, and stamped into $\varnothing 6.2 \mathrm{~mm}$ discs on a CNC turret punch press (Amada Arcade, Japan). Prior to surface treatment, to remove any machining contaminant and reveal the native surface, discs were successively washed in five steps:

- first, in 70\% vol. ethanol;

- second, for 5 minutes at $40^{\circ} \mathrm{C}$ in an ultrasonic bath with deionized water Milli-Q Direct (Millipore, Billerica, MA) with a resistivity of $18.2 \mathrm{M} \Omega \mathrm{cm}$ at $25^{\circ} \mathrm{C}$;

- $\quad$ third, in $40 \% \mathrm{NaOH}$ and water bath for 5 minutes;

- forth, sonicated in deionized water for 5 minutes with a subsequent rinse with deionized water for 5 minutes;

- fifth, immersed for 10 minutes in $50 \%$ vol. $\mathrm{HNO}_{3}$, then sonicated in deionized water for 5 minutes, and then rinsed in deionized water until reaching a neutral $\mathrm{pH}$, and finally, stored in $70 \%$ vol. ethanol.

\subsection{Deposition of the coating}

Samples were either coated with pyrogallol (PG) diluted into BisTris buffer $\mathrm{pH} \quad 7.0$ with $100 \mathrm{mM} \quad \mathrm{MgCl}_{2}$ at a concentration of $1 \mathrm{mg} \mathrm{mL}^{-1}$ or with tannic acid (TA) diluted into bicine buffer $\mathrm{pH} 7.8$ with $100 \mathrm{mM} \mathrm{NaCl}$ at $1 \mathrm{mg} \mathrm{mL}^{-1}$ [12]. After agitating the samples in diluted solutions for $24 \mathrm{~h}$ on a rocking machine at 30 oscillations $\min ^{-1}$ at room temperature, the samples were thoroughly rinsed with deionised water and dried by blowing nitrogen to prevent further oxidation before storage in a dry polyethylene well plate. Non-coated nickel-titanium samples were used as control surfaces.

\subsection{Solutions and reagents}

The electrolyte solution used for all experiments was a 0.2 $\mathrm{M}$ phosphate buffer saline tablets (Sigma-Alrich Chemie Gmgh, P-4417) dissolved in deionised water Milli-Q Direct (Millipore, Billerica, MA) with a resistivity of $18.2 \mathrm{M} \Omega \mathrm{cm}$ at $25^{\circ} \mathrm{C}$ and mixed with $30 \%$ BSA (Sigma-Alrich Chemie Gmgh, A-7284) at a concentration of $3 \mathrm{~g} \mathrm{~L}^{-1}$, here referred to as PBS+BSA. The concentration of proteins was chosen based on the concentration ratio in human blood as suggested by previous studies $[14,15]$. The protein solution prepared at $\mathrm{pH} 7.4$ was allowed to equilibrate for at least 30 min in a constant temperature bath at $37 \pm 1{ }^{\circ} \mathrm{C}$, stirred at 100 rpm on a magnetic stirrer hotplate RCT standard (IKA works, NC).

\subsection{Electrochemical tests}

The counter electrode for each experiment was a coiled $\mathrm{Pt}$ wire and the reference electrode was an $\mathrm{Ag} / \mathrm{AgCl}$ reference electrode with $0.15 \mathrm{M} \mathrm{KCl}$ (Aldrich, 99.999\% metals basis). The temperature of the electrolyte was maintained at $37 \pm 1$
${ }^{\circ} \mathrm{C}$ to mimic in vivo conditions. Nickel-titanium samples were placed on electrode holders exposing a test surface of $0.3 \mathrm{~cm}^{2}$ with a density of $6.45 \mathrm{~g} \mathrm{~cm}^{-3}$ and an equivalent weight of $17.8 \mathrm{~g}$, immersed in a $20 \mathrm{~mL}$ electrolytic solution deaerated by bubbling within nitrogen gas for 30 min prior to EIS. Measurements were performed on a 3000 Gamry potentiostat/galvanostat ZRA (Gamry Instruments Inc., Warminster, PA), and data were analysed with Gamry Echem Analyst 7.03 software (Gamry Instruments Inc., Warminster, PA). EIS tests were carried out at OCP with 10 $\mathrm{mV}$ of signal amplitude and a frequency range from $50 \mathrm{kHz}$ to $0.01 \mathrm{~Hz}$. EIS measurements were performed subsequently after 1, 3, 6, 12 and $24 \mathrm{~h}$ prior each OCP. A simplex method was used to fit data to the equivalent circuit. Finally, cyclic voltammetric tests were measured at a scan rate of $10 \mathrm{mV} / \mathrm{s}$ with a step size of $2 \mathrm{mV}$ within a potential range between -1 to $1.5 \mathrm{~V}$ vs. $\mathrm{Ag} / \mathrm{Ag} \mathrm{Cl}$.

\subsection{Ni ion release}

The amount of nickel ions released was investigated using the flame atomic adsorption spectrometer AAnalyst 400 (Perkin Elmer, Inc. USA). Samples were immersed in $5 \mathrm{~mL}$ PBS+BSA solution in eppendorf tubes and incubated at $37 \pm$ $0.5{ }^{\circ} \mathrm{C}$ to mimic in vivo conditions. After samples were removed, nickel concentration readings were cumulatively recorded at segmented intervals $(1,3,7,14$ and 28 days). Triplicate samples were exposed in parallel for each coating and time period.

\section{Results and Discussion}

\subsection{Open circuit potential}

The OCP can monitor the formation of protective films on the surface of the electrode [16]. The increase of OCP indicates the formation of a passive film, and a decrease is indicative of its breakage, dissolution, or non-formation, and a value without significant variation indicates a stable surface[16, 17]. For the control surface, OCPs recorded in Fig. 1: A, vary in the range from -315.1 to $-149.7 \mathrm{mV}$; the increasing of $\mathrm{E}_{\mathrm{OCP}}$ indicated a double layer formation on the surface from the first $12 \mathrm{~h}$ of the experiment (protein adsorption). After $12 \mathrm{~h}$, steady-state OCP values reached up to $24 \mathrm{~h}$ of exposure in PBS+BSA, which is an indication of possible saturation of protein adsorption which purportedly stabilises the corrosion process [18].

For the PG coated sample, OCP varies from -391.0 to $146.7 \mathrm{mV}$, as seen in Fig.1: B shows some $\mathrm{E}_{\mathrm{OCP}}$ fluctuations after $12 \mathrm{~h}$ indicating the disruptive passive layer behaviour as a result of the continuous deposition-dissolution process on the metal surface. On the contrary for TA coated surface, OCP varying from -164.4 to $-48.1 \mathrm{mV}$; it is interesting to note that, all $\mathrm{E}_{\mathrm{OCP}}$ curves were relatively flat with no major fluctuation, indicating stable surface despite the constant adsorption of proteins within the negative potential region as seen in Fig. 1: C.

In the PBS+BSA medium, corrosion potentials measured in open circuit on control, PG and TA samples were evolving towards more anodic potentials (more noble) until reaching a steady-state value of potential. A previous study has also demonstrated that BSA containing electrolyte causes a shift of corrosion potential toward more positive OCPs [19]; an increase of the potential toward more positive values is an indication of the passive layer formation [20], consequently the adsorption layer of BSA on the working electrode works as a surface film. Conti et al. have also 
shown that during the static immersion degradation tests, the presence of a biofilm developing on the surface due to protein additions may have caused the elution of ions from the surface of the alloy to decrease [21]. This may have been caused by the inability of the dissolved oxygen to reach the surface in the presence of the biofilm, thereby starving the cathodic part of the reaction, which, in turn, would have led to a deceleration of the anodic reaction, leading to a reduction in metal ion dissolution [21]. To ensure a more thorough characterization of the electrode / electrolyte interface and processes that occur on the samples surface, EIS measurements were conducted in a wide frequency range after OCP stabilization of the different testing electrodes.
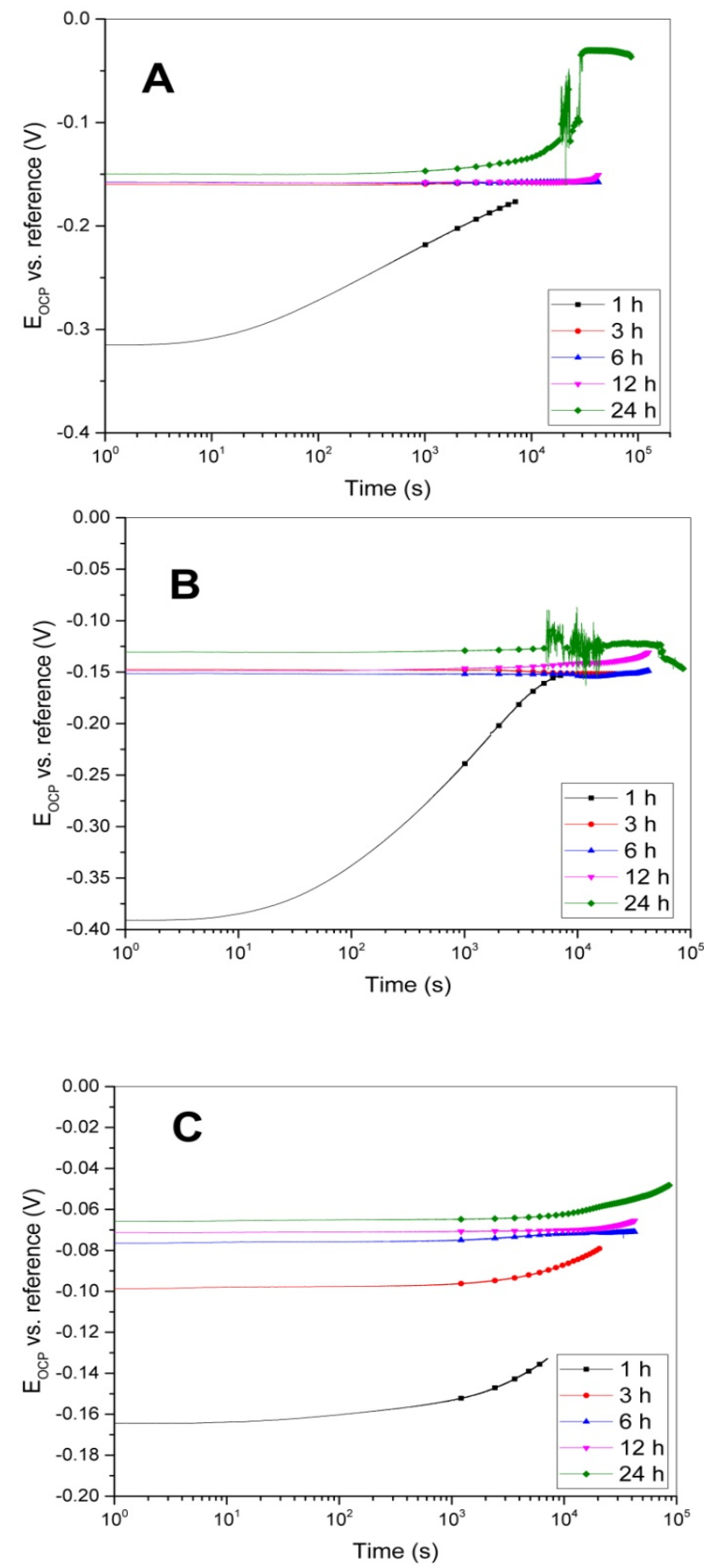

Fig. 1: Open circuit potentials for control (A), PG coated nickeltitanium (B) and TA coated nickel-titanium (C) measured for 1, 3, 6, 12 and $12 \mathrm{~h}$ in PBS+BSA

\subsection{EIS}

This study did not take into account the use of probe molecules as Oliveira and Melo [22] demonstrated the advantages of using a method that does not require the presence of probe molecules whose interaction with surfaceactive agents is unavoidable and have a big impact on the quality of the data obtained. Bode and Nyquist diagrams are presented in Fig 2.
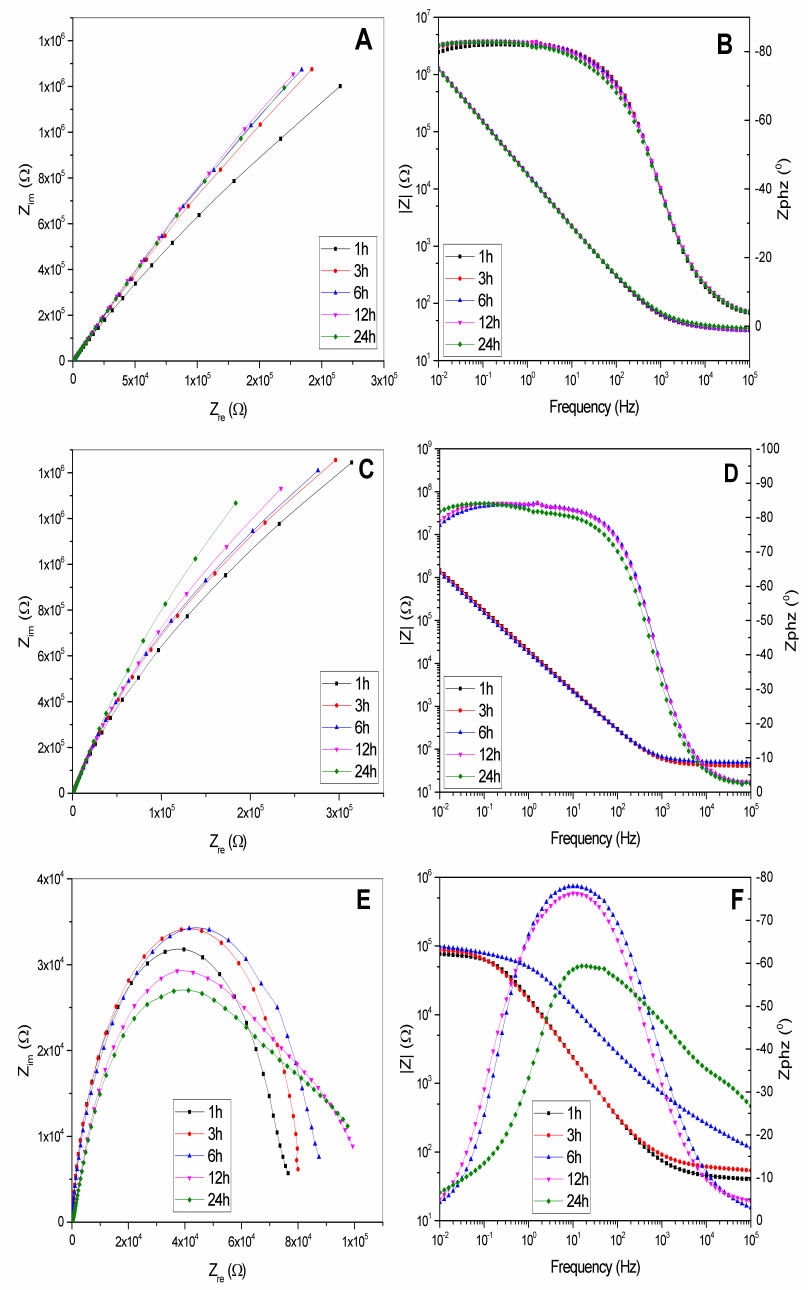

Fig. 2: Nyquist and Bode plots at different immersion times respectively for control (A and B), PG coated nickel-titanium (C and D) and TA coated nickel-titanium (E and F) measured for 1, 3, 6, 12 and $12 \mathrm{~h}$ in PBS+BSA

The equivalent electrical circuit model that was used to fit the experimental data is given in Fig. 3. For the uncoated control sample, a Randles circuit with an added diffusion element $(\mathrm{W})$ in parallel with the charge transfer resistance $\left(\mathrm{R}_{\mathrm{ct}}\right)$ were added in order to account for the diffusion of the electroactive species in the nitinol/solution interface (Fig. $3 \mathrm{~A})$. For the coated samples, as suggested in the literature, a modified Randles circuit was used to model protein adsorption at the surface of the electrode [23-25]. A two time constant circuit was found to be the most suitable (Fig. $3 \mathrm{~B})$. The fitting quality (goodness of fit) was established from low percent errors (less than 5\%) in parameters and the chi-squared values, which were in the order of $10^{-4}$, indicating a good agreement between the experimental results and fittings. Tables 1, 2 and 3 summarise the impedance parameters fitted to the equivalent circuit for each studied surface. 

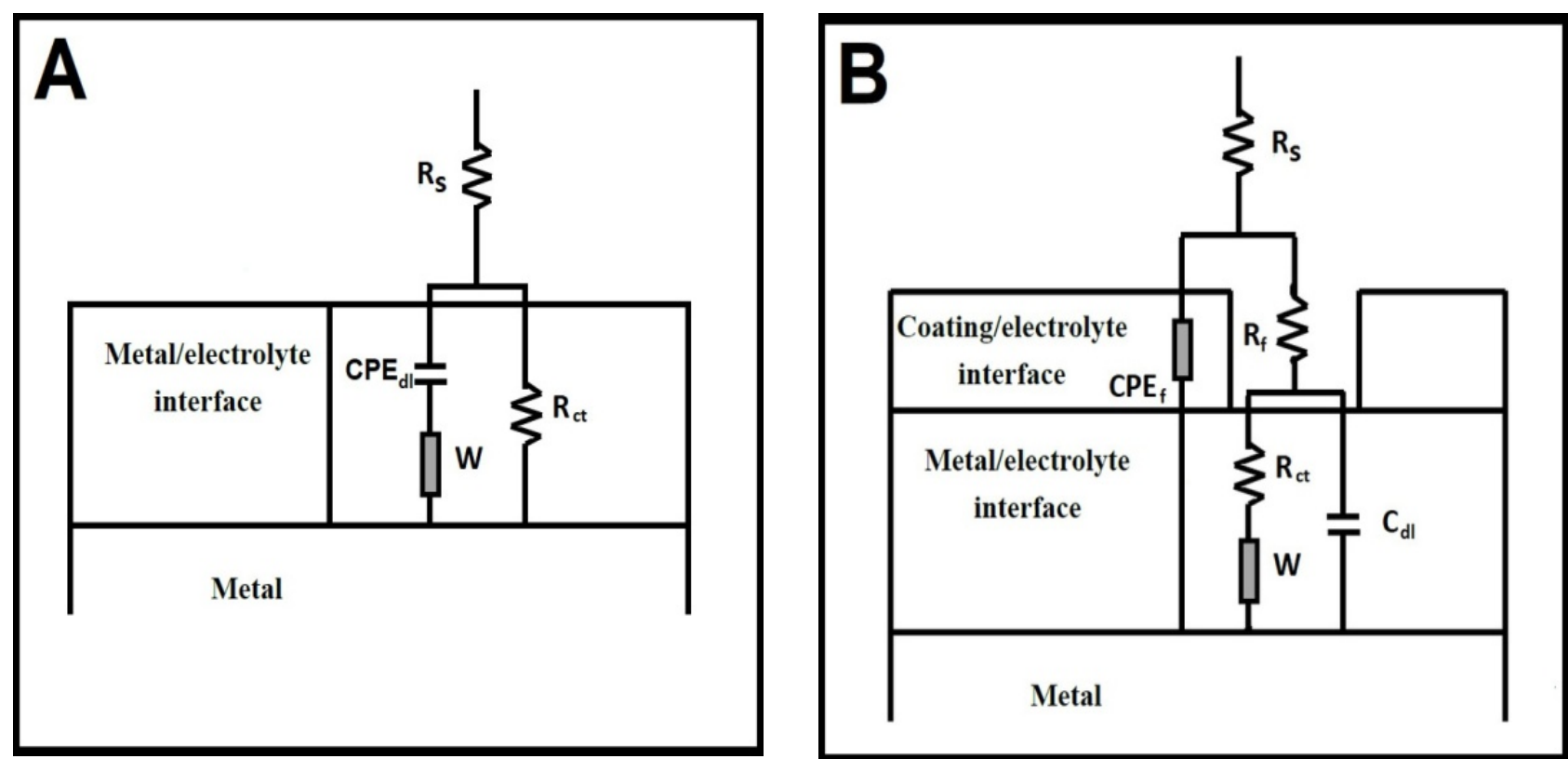

Fig. 3: Physical model and equivalent circuits used for modelling the impedance spectra of the control (A) and the phenolic coated nitinol samples (B) $\left(\mathrm{R}_{\mathrm{s}}\right.$ - resistance of the solution, $\mathrm{R}_{\mathrm{ct}}$ - charge transfer resistance, $\mathrm{C}_{\mathrm{dl}}$ - capacitance of the electrical double layer between solution and outer, probably porous layer, $\mathrm{R}_{\mathrm{f}}$ - electrolytic resistance through the passive layer, $\mathrm{CPE}_{\mathrm{f}}-$ capacity of the passive film, $\mathrm{CPE} \mathrm{dl}_{\mathrm{d}}-\mathrm{Double}$ layer constant phase element, $\mathrm{W}$ - Warburg impedenc)

Table 1. Impedance parameters fitted for the control surface from the equivalent circuit

\begin{tabular}{|c|c|c|c|c|c|c|c|}
\hline & \multirow[b]{2}{*}{$\mathrm{R}_{\mathrm{s}} / \Omega$} & \multicolumn{2}{|l|}{$\mathrm{CPE}$} & \multirow[b]{2}{*}{$\mathrm{R}_{\mathrm{ct}} / \Omega$} & \multicolumn{3}{|l|}{ W } \\
\hline & & $Q_{d l} / \mathrm{S}^{*} \mathrm{~s}^{n}$ & $n$ & & $\mathrm{~W}-\mathrm{R} / \Omega$ & $\mathrm{B} / \mathrm{s}^{1 / 2}$ & W-P \\
\hline $1 \mathrm{~h}$ & 32.84 & $1.97 \times 10^{-5}$ & 0.84 & $1.35 \times 10^{7}$ & 29.95 & $6.6 \times 10^{-4}$ & 0.5 \\
\hline $3 \mathrm{~h}$ & 32.73 & $2.23 \times 10^{-5}$ & 0.83 & $1.71 \times 10^{7}$ & 30.65 & $5.5 \times 10^{-4}$ & 0.5 \\
\hline $6 \mathrm{~h}$ & 32.37 & $2.5 \times 10^{-5}$ & 0.82 & $1.69 \times 10^{7}$ & 29.95 & $5.0 \times 10^{-4}$ & 0.5 \\
\hline $12 \mathrm{~h}$ & 32.31 & $3.07 \times 10^{-5}$ & 0.80 & $1.44 \times 10^{7}$ & 26.07 & $4.0 \times 10^{-4}$ & 0.5 \\
\hline $24 \mathrm{~h}$ & 35.21 & $3.25 \times 10^{-5}$ & 0.78 & $1.36 \times 10^{7}$ & 24.61 & $4.0 \times 10^{-4}$ & 0.5 \\
\hline
\end{tabular}

$\mathrm{R}_{\mathrm{s}}$ : solution resistance; CPE: constant phase element; $\mathrm{Q}_{\mathrm{dl}}$ : combination of properties related to both the double layer and the electroactive species; $n$ : CPE constant parameter; $\mathrm{R}_{\mathrm{ct}}$ : charge-transfer resistance; W-R: Diffusion resistance, B: diffusion factor, W-P: exponent "fixed" at 0.5 for a pure diffusional behavior.

Table 2. Impedance parameters fitted for the PG coatings from the equivalent circuit

\begin{tabular}{|c|c|c|c|c|c|c|c|c|}
\hline & \multirow[b]{2}{*}{$\mathrm{R}_{\mathrm{s}} / \Omega$} & \multicolumn{2}{|l|}{$\mathrm{CPE}_{\mathrm{f}}$} & \multirow[b]{2}{*}{$\mathrm{R}_{\mathrm{f}} / \Omega$} & \multirow[b]{2}{*}{$\mathrm{C}_{\mathrm{dl}} / \mathrm{F}$} & \multirow[b]{2}{*}{$\mathrm{R}_{\mathrm{ct}} / \Omega$} & \multicolumn{2}{|l|}{$\mathrm{W} \mid$} \\
\hline & & $Q_{f} / \mathrm{S}^{*} \mathrm{~s}^{n}$ & $n$ & & & & $\mathrm{Y}_{0} / \mathrm{S} * \mathrm{~s}^{1 / 2}$ & $\mathrm{~B} / \mathrm{s}^{1 / 2}$ \\
\hline $1 \mathrm{~h}$ & 41.34 & $7.26 \times 10^{-3}$ & $9.11 \times 10^{-1}$ & 55.53 & $1.37 \times 10^{-3}$ & $5.18 \times 10^{6}$ & $7.42 \times 10^{-3}$ & $3.92 \times 10^{-2}$ \\
\hline $3 \mathrm{~h}$ & 41.08 & $6.81 \times 10^{-3}$ & $9.08 \times 10^{-1}$ & 32.43 & $1.54 \times 10^{-3}$ & $0.39 \times 10^{1}$ & $1.01 \times 10^{-5}$ & $5.69 \times 10^{-2}$ \\
\hline $6 \mathrm{~h}$ & 41.20 & $7.20 \times 10^{-3}$ & $9.09 \times 10^{-1}$ & 42.74 & $1.42 \times 10^{-3}$ & $1.24 \times 10^{2}$ & $9.14 \times 10^{-3}$ & $6.47 \times 10^{-2}$ \\
\hline $12 \mathrm{~h}$ & 41.19 & $8.02 \times 10^{-3}$ & $9.08 \times 10^{-1}$ & 79.39 & $1.23 \times 10^{-3}$ & $5.83 \times 10^{6}$ & $6.09 \times 10^{-5}$ & $0.85 \times 10^{-1}$ \\
\hline $24 \mathrm{~h}$ & 49.54 & $8.66 \times 10^{-3}$ & $9.12 \times 10^{-1}$ & 256.50 & $9.66 \times 10^{-7}$ & $1.52 \times 10^{4}$ & $0.12 \times 10^{-1}$ & $6.05 \times 10^{-4}$ \\
\hline
\end{tabular}

$\mathrm{R}_{\mathrm{s}}$ : solution resistance; CPE: constant phase element; $\mathrm{Q}_{\mathrm{f}}$ : combination of properties related to both the surface and the electroactive species; $n$ : CPE constant parameter; $\mathrm{R}_{\mathrm{f}}$ : Resistance of the film/coating; $\mathrm{R}_{\mathrm{ct}}$ : charge-transfer resistance; $\mathrm{C}_{\mathrm{dl}}$ : double layer capacitance; W|: bounded Warburg impedance; $\mathrm{Y}_{0}$ : admittance; B: diffusion factor.

Table 3. Impedance parameters fitted for the TA coatings from the equivalent circuit

\begin{tabular}{|c|c|c|c|c|c|c|c|c|}
\hline & \multirow[b]{2}{*}{$\mathrm{R}_{\mathrm{s}} / \Omega$} & \multicolumn{2}{|l|}{$\mathrm{CPE}_{\mathrm{f}}$} & \multirow[b]{2}{*}{$\mathrm{R}_{\mathrm{f}} / \Omega$} & \multirow[b]{2}{*}{$\mathrm{C}_{\mathrm{dl}} / \mathrm{F}$} & \multirow[b]{2}{*}{$\mathrm{R}_{\mathrm{ct}} / \Omega$} & \multicolumn{2}{|l|}{$\mathrm{W} \vdots$} \\
\hline & & $Q_{f} / \mathrm{S}^{*} \mathrm{~s}^{n}$ & $n$ & & & & $\mathrm{Y}_{0} / \mathrm{S} * \mathrm{~s}^{1 / 2}$ & $\mathrm{~B} / \mathrm{s}^{1 / 2}$ \\
\hline $1 \mathrm{~h}$ & 41.33 & $9.84 \times 10^{-3}$ & $8.49 \times 10^{-1}$ & $1.84 \times 10^{2}$ & $1.43 \times 10^{-3}$ & $1.87 \times 10^{5}$ & $3.20 \times 10^{-3}$ & $5.25 \times 10^{-2}$ \\
\hline $3 \mathrm{~h}$ & 49.93 & $9.05 \times 10^{-3}$ & $8.52 \times 10^{-1}$ & $1.91 \times 10^{2}$ & $1.67 \times 10^{-3}$ & $1.69 \times 10^{4}$ & $4.33 \times 10^{-7}$ & $2.85 \times 10^{-2}$ \\
\hline $6 \mathrm{~h}$ & 55.63 & $1.04 \times 10^{-5}$ & $8.27 \times 10^{-1}$ & $1.69 \times 10^{2}$ & $1.67 \times 10^{-3}$ & $8.80 \times 10^{4}$ & $7.77 \times 10^{-4}$ & $7.98 \times 10^{-2}$ \\
\hline $12 \mathrm{~h}$ & 83.40 & $3.83 \times 10^{-3}$ & $6.49 \times 10^{-1}$ & $2.06 \times 10^{4}$ & $2.28 \times 10^{-7}$ & $7.72 \times 10^{4}$ & $7.92 \times 10^{-3}$ & $1.61 \times 10^{-1}$ \\
\hline $24 \mathrm{~h}$ & 105.30 & $4.86 \times 10^{-3}$ & $6.53 \times 10^{-1}$ & $9.91 \times 10^{4}$ & $0.21 \times 10^{-1}$ & $1.41 \times 10^{4}$ & $2.52 \times 10^{-4}$ & $2.86 \times 10^{-1}$ \\
\hline
\end{tabular}

$\mathrm{R}_{\mathrm{s}}$ : solution resistance; CPE: constant phase element; $\mathrm{Q}_{\mathrm{f}}$ : combination of properties related to both the surface and the electroactive species; $n$ : CPE constant parameter; $\mathrm{R}_{\mathrm{f}}$ : Resistance of the film/coating; $\mathrm{R}_{\mathrm{ct}}$ : charge-transfer resistance; $\mathrm{C}_{\mathrm{dl}}$ : double layer capacitance; W : porous bounded $\mathrm{Warburg}$; $\mathrm{Y}_{0}$ : admittance; $\mathrm{B}$ : diffusion factor. $\mathrm{CPE}_{\mathrm{f}}$ accounts for inhomogeneities in the adsorbed BSA film. The equivalent circuit models a porous, insulating film on the surface, indicating that BSA film on the surface is not a homogenous monolayer. 


\subsubsection{Equivalent electrical circuit analysis}

\subsubsection{Solution resistance, $\mathbf{R}_{\mathrm{s}}$}

This is also referred to as the uncompensated resistance between the reference and the working electrode [26], as well as ohmic resistances due to contacts, wires, etc. In all three cases (control, TA and PG coated samples) as shown on Tables 1, 2 and 3, the solution conductance decreased as the electrolyte resistance increased, especially after $12 \mathrm{~h}$ to $24 \mathrm{~h}$. This is supposedly caused by the BSA adsorption occurrence on the surface of the working electrode becoming more passive. It was also noticeable that $\mathrm{R}_{\mathrm{s}}$ values were higher (less conductive) for PG and TA coated samples than for uncoated metal (control group), an observation also reported by Nicholson on untreated surfaces [26, 27]. Many factors influence the uncompensated resistance, among the factors are the shape and size of the cell, the location of the reference electrode, the shape of the working electrode, and the size and position of the counter electrode [28, 29]. To minimise the ohmic drop of the electrolyte, Elgrish et al. proposed to decrease $\mathrm{R}_{\mathrm{s}}$ directly by diminishing the distance separating the reference and working electrodes [30]. In the present study, this distance was kept at $5 \mathrm{~mm}$. Despite having the same ionic composition, the difference of $\mathrm{R}_{\mathrm{s}}$ observed in the PBS+BSA electrolytic solution for all 3 types of surfaces herein studied, is purportedly due to the type of surface and its adsorption ability.

\subsubsection{Constant phase element, $\mathrm{CPE}$}

CPEs were introduced instead of pure capacitors in the fitting procedure in order to obtain good agreement between the simulated and experimental data. The use of the CPE element accounts for the non-ideal behaviour of the capacitive elements.

From Table 2, the CPE measured on the PG coated nickeltitanium surfaces behaved like ideal capacitors $(n \approx 1)$, while in Table 3, this behaviour in the TA coated group between 12 and $24 \mathrm{~h}$, changed to a Warburg diffusion component ( $n$ $\approx 0.5$ ). The drop of the $\mathrm{Q}_{\mathrm{f}}$ and $n$ values in the TA group suggests the development of a more porous coating layer, in agreement with Chembath et al. [31]. This is reflected in the $\mathrm{CPE}$ values which follow the order $\mathrm{TA}<\mathrm{PG}$ after $24 \mathrm{~h}$ immersion in the PBS+BSA solution.

\subsubsection{Resistance of the film/coating, $\mathbf{R}_{\mathbf{f}}$}

For the modified samples on Tables 2 and 3, the resistance on the outer thin film increases with the immersion time, and TA coating is more electrically resistive than PG. This means that an oxide barrier layer is formed on the surface, which becomes more corrosive resistive. This is supposedly due to the physicochemical nature of each coating, and ability to adsorb the proteins and stabilize the surface [32]. The structure of tannic acid is comprised of an extended network of $-\mathrm{OH}$ groups, which apparently can be absorbed and protect the underlying nitinol surface more efficiently. The aqueous stability of phenolic coatings can also play a role on $R_{f}$. In fact, in a previous study [11], the aqueous stability was evaluated by comparing the final and initial coating thickness after immersion of samples in a phosphate buffer at $\mathrm{pH}$ 7.0. It was found that TA thickness was reduced to $60 \%$ after 7 days of immersion whilst PG thickness remained stable and significantly unchanged. In our case and in presence of PBS+BSA, we observed that the TA coating on the nitinol surface already from the beginning of the process had a much higher film resistance, indicating better anticorrosion behaviour than PG.

\subsubsection{Charge-transfer resistance, $\mathbf{R}_{\mathrm{ct}}$}

In the case where a protein film is formed on the electrode surface, adsorption of BSA molecules to the electrode surface was predicted to result in increase in the chargetransfer resistance [24]. Taking into account the two measurement extrema ( 1 and $24 \mathrm{~h}$ ); it can be seen that the impedance decreased tenfold for TA and a hundred times for the PG coating, and is almost steady for the uncoated control sample. This is an indication that a less electroactive surface is developed on TA than on the PG coated surfaces and a protein layer with constant characteristics was reportedly adsorbed on the untreated nickel-titanium control. It should be noted though that the native nitinol surface shows quite high $\mathrm{R}_{\mathrm{ct}}$ that stays practically unchanged during our experimental timeframe. This implies the good blocking behaviour of nitinol under these conditions and it is related to the rapid formation of an oxide film, mainly attributed to $\mathrm{TiO}_{2}[33,34]$. As observed by Wang and Zheng [35], a nickel deficiency may be caused on the surface of the passivated nitinol, and nickel may diffuse into the sublayer or be released into the electrolyte. The latter will be assessed later as we will see from the Ni ion release experiments.

\subsubsection{Double layer capacitance, $C_{d l}$}

As BSA is adsorbed on the working electrode, the thickness of the film increases, consequently a decrease of $\mathrm{C}_{\mathrm{dl}}$ is expected $[24,36] . \mathrm{C}_{\mathrm{dl}}$ increases slightly in the control group (from 2 to $3.3 \mathrm{mF}$ ), perhaps an indication of an adsorbed layer with decreasing thickness throughout the immersion period. This correlates well with the high blocking behaviour of the control sample, which implies the low affinity of BSA with the oxidised nitinol surface. On the other hand, in the PG and TA coatings, it is more or less constant for the $12 \mathrm{~h}$ and $6 \mathrm{~h}$ mark, respectively, suggesting a constant film thickness. At the end of the process, the TA $\mathrm{C}_{\mathrm{dl}}$ is much higher than that of the $\mathrm{PG}$, indicating a thinner BSA film formation on the TA coating. It can be suggested that the TA coating shows a lower affinity towards the absorption of BSA, compared to the $\mathrm{PG}$, which capacitance drops suggesting an increasing accumulation of BSA.

\subsubsection{Warburg impedance, $W$}

The Warburg element (W), describing the process of diffusion, is characterized by an admittance parameter, $\mathrm{Y}_{0}$ $\left(\mathrm{S}^{*} \mathrm{~s}^{1 / 2}\right)$, and a diffusion factor, $\mathrm{B}\left(\mathrm{s}^{1 / 2}\right)$. Based on Nyquist plots and the match of fitting models, the bounded Warburg impedance (W|) with no diffusion behaviour matched for PG coatings and the control group, whereas TA coatings were of the nature of porous bounded Warburg (W:) with diffusion. This element improves the fitting by taking into account the diffusional contribution of the electroactive species.

\subsection{Nickel ions release}

The concentration of released nickel ions (in $\mu \mathrm{g} \mathrm{L}^{-1}$ ) in proteinaceous media recorded for control, PG and TA samples fell respectively in the range $(0.077-0.146),(0.082$ $-0.196)$ and $(0.086-0.152)$. These concentrations were lower than those defined for human serum $\left(0.1-1.3 \mu \mathrm{g} \mathrm{L}^{-1}\right)$, blood $\left(0.6-1.8 \mu \mathrm{g} \mathrm{L}^{-1}\right)$, and urine $\left(0.5-6.0 \mu \mathrm{g} \mathrm{L}^{-1}\right)$ of healthy adults as established by the TRACY protocol [37]. Fig. 4 shows $\mathrm{Ni}$ ion concentrations increasing with immersion time. Since the slope of the curve in Fig. 4 is equal to the Ni release rate, it is clear that the nickel release 
rate varies with immersion time and is higher between 14 and 28 days.

It can thus be inferred that the increase in the release rate is related to the partial dissolution of the outer layer on the nickel-titanium surfaces. The increased concentration of $\mathrm{Ni}$ ions detected in PBS+BSA indicates that Ni leaching from nitinol surface takes place even when no visual corrosion signs occurred; this selective leaching of nickel from nickeltitanium surface causes a denickelification of the alloy, in accordance with the observations of Wang and Zheng [35], this process releases nickel ions. Nickel released from the bulk material into the solution reduces the local concentration of nickel in the materials. $\mathrm{NaCl}$ from PBS is the main causal agent that renders the original thin oxide layer on the nickel-titanium surface vulnerable after $\mathrm{Ni}-\mathrm{Ti}$ bond is attacked by $\mathrm{Cl}^{-}$[38]. Moreover, the contribution of BSA is also to be taken into account. Omanovic and Roscoe provided a holistic explanation of the mechanism of BSA adsorption proposed to involve the interaction of the negatively charged carboxylate groups of the proteins as anchoring sites between the proteins and the surface [13].

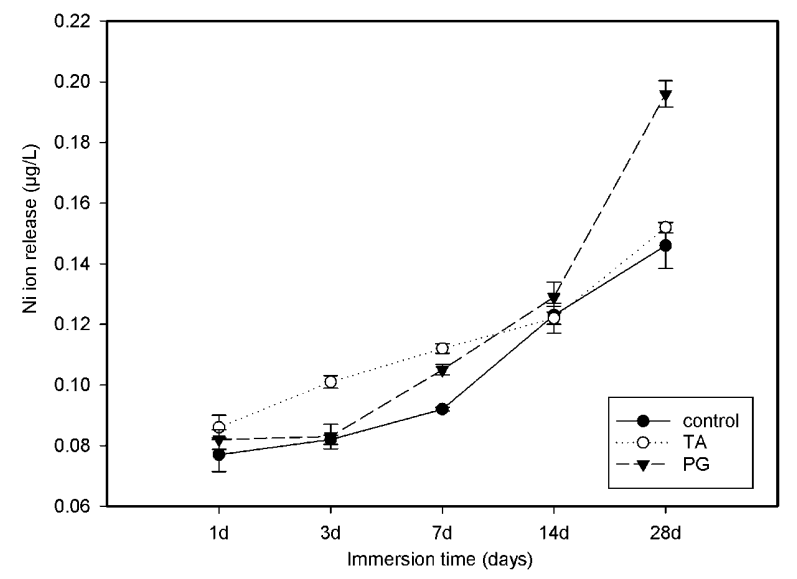

Fig. 4: Nickel ion release in PBS+BSA after exposure for 1, $3,7,14$ and 28 days at $37^{\circ} \mathrm{C}$

Fig. 4 shows that nickel-titanium in PBS+BSA led to Ni ion leaching from the first day of exposure; this behaviour of transition metals in proteinaceous electrolyte has also been investigated by Lin et al. who observed that proteins enhanced the corrosion of first row transition metals due to their ability to form complexes [10]. Omanovic and Roscoe also stated that complexing of metal ions by proteins may reduce the activation energy or increase the chemical free energy change associated with metal dissolution and enhance the corrosion rate of metals [13]. This complexication leading to the chelation of passive filmforming elements may disturb the local chemical equilibrium, causing film dissolution and exposure of the underlying metal surface [13]. Protein-catalyzed dissolution of these metals was also suggested, and the predominant form of the corrosion product of these metals was a metalligand complex, with the hydroxides of these metals complexing directly with albumin [13]. Valenti et al. showed that histidine residues (present in the carboxylate binding site of albumin) bind with high affinity to nickel ions immobilized on chelating sorbent surfaces [39]. This explains the fact that our EIS results revealed that BSA was constantly adsorbed on uncoated nickel-titanium samples (chelating sorbent surfaces) rather than on phenolic-coated samples that already form metal ion complexication during the coating process [11], purportedly leaving fewer binding sites for BSA, providing room for adsorption/desorption shifts.

\subsection{Cyclic voltammetry}

We now drive each material beyond its equilibrium (OCP) and an externally applied field is imposed. From the voltammograms in Fig. 5, it can be seen that the control sample shows an ohmic behaviour, whereas the TA and PG coated present a blocking one. Both modified samples do not show significant current density in a potential window of 2.5 $\mathrm{V}$, with the $\mathrm{PG}$ to appear slightly more blocking than the TA.

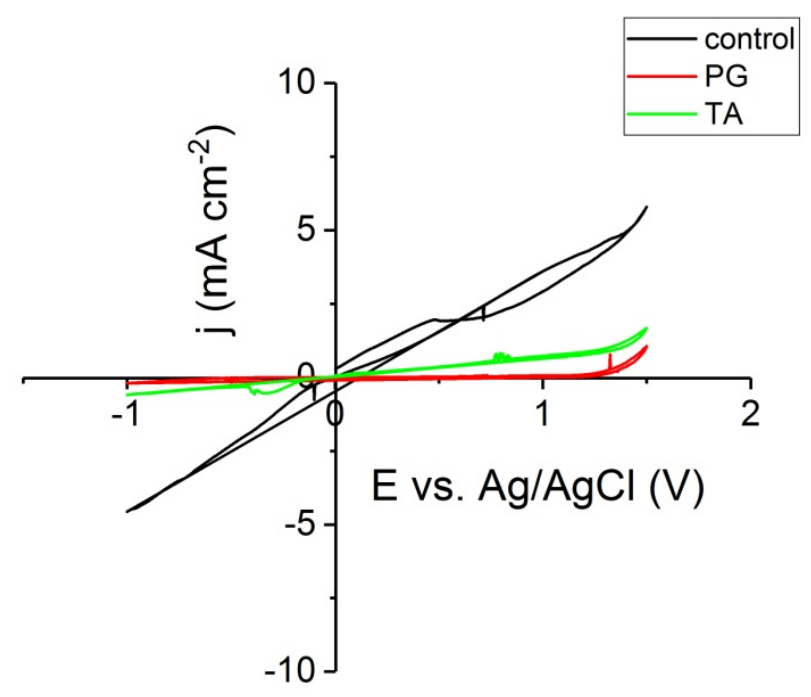

Fig. 5: Cyclic voltammograms of control, TA and PG in PBS+BSA buffer with scan rate of $10 \mathrm{mV} \mathrm{s}^{-1}$

We speculate that this behaviour is related to the coating capacitance that is added in parallel to the capacitance of the native oxide on the nitinol surface. From Tables 1, 2 and 3 we see that the sum of the two capacitances of the TA and PG samples are much higher that of the control sample, implying a higher charge transfer resistance when field is applied and charges are forced to move through the interfaces. It should be mentioned again that the CPEs reflect the apparent capacitances, as the exponent values are in general higher than $0.8[40,41]$. Moreover, the solution resistance, $\mathrm{R}_{\mathrm{s}}$, increases from the control $<\mathrm{TA}<\mathrm{PG}$, a fact that also contributes to the overall resistance during the $\mathrm{CV}$ experiments.

In all considered surfaces for this study, proteins tend to accumulate differently at interfacial regions. This occurrence can be an advantage or a disadvantage depending on the application of the biomaterial. On one hand, for bone anchored implants, such as dental implants or artificial hip joints, the clinical goal is to obtain a long term secure anchoring of the implant. Achieving this function with the shortest possible healing-time is of relevance and can be favoured with a guided protein adsorption resulting in a beneficial induction of bone formation. On the other side, the engineering of blood-compatible materials, e.g. artificial blood vessels or heart valves, has the main goal of suppressing blood coagulation on antifouling surfaces. Understanding and controlling the surface characteristics of these surfaces will also be crucial for controlling protein adsorption $[42,43]$. 


\section{Conclusion}

In this study, we investigated the BSA adsorption on phenolic-coated nickel-titanium for probable application on implantable biomaterials. It was found that

- The native nitinol surface (control sample) shows very good antifouling behaviour when the material is under equilibrium conditions. Under an externally applied field, the control sample shows the lowest blocking behaviour most probably due to the missing blocking ability of the phenolic coating, i.e. it misses a capacitance due to the coating.

- TA coating on nickel-titanium shows the lowest affinity towards the BSA absorption. Whilst the PG shows the highest affinity and a thicker protein film formation is suggested, that led to higher electrochemical activity and $\mathrm{Ni}$ ion release into the PBS+BSA solution after 28 days of immersion.

- It should be noted that in all cases, the quantity of nickel ions eluted out of the medium was low and fell within an acceptable range of biocompatibility, which is defined for human serum $\left(0.1-1.3 \mu \mathrm{g} \mathrm{\textrm {L } ^ { - }}\right.$ $\left.{ }^{1}\right)$, blood $\left(0.6-1.8 \mu \mathrm{g} \mathrm{L}^{-1}\right)$, and urine $(0.5-6.0 \mu \mathrm{g}$

$\left.\mathrm{L}^{-1}\right)$ of healthy adults.

In conclusion, coating TA on nitinol appears to be desirable for biomaterial applications whereas biocompatibility is enhanced by protein adsorption, while PG coating may lead to side effects especially on patients with nickel hypersensitivity.

It is also worth noting the importance of this study in biomaterials assessment for biocompatibility, as well as biosensing with the use of powerful electrochemical techniques, which can elucidate the interaction of proteins with inorganic surfaces.

\section{Acknowledgements}

The authors thank Jonsky G. for the AAS analysis, Prof. Truls Norby from the Group for Electrochemistry at the University of Oslo (ELCHEM) for providing experimental equipment.

This is an Open Access article distributed under the terms of the Creative Commons Attribution License

\section{References}

[1] Trzeciakiewicz H, Esteves-Villanueva J, Soudy R, Kaur K, MarticMilne S. Electrochemical characterization of protein adsorption onto YNGRT-Au and VLGXE-Au surfaces. Sensors. 2015; 15:19429-42.

[2] Hlady V, Buijs J. Protein adsorption on solid surfaces. Curr Opin Biotechnol. 1996;7:72-7.

[3] Annarelli C, Fornazero J, Cohen R, Bert J, Besse J-L. Colloidal protein solutions as a new standard sensor for adhesive wettability measurements. J Colloid Interface Sci. 1999;213:386-94.

[4] Imamura K, Shimomura M, Nagai S, Akamatsu M, Nakanishi K. Adsorption characteristics of various proteins to a titanium surface. J Biosci Bioeng. 2008;106:273-8.

[5] Oliva FY, Avalle LB, Cámara OR, De Pauli CP. Adsorption of human serum albumin (HSA) onto colloidal TiO 2 particles, Part I. J Colloid Interface Sci. 2003;261:299-311.

[6] Thierry B, Merhi Y, Bilodeau L, Trepanier C, Tabrizian M. Nitinol versus stainless steel stents: acute thrombogenicity study in an ex vivo porcine model. Biomaterials. 2002;23:2997-3005.

[7] Michiardi A, Aparicio C, Ratner BD, Planell JA, Gil J. The influence of surface energy on competitive protein adsorption on oxidized NiTi surfaces. Biomaterials. 2007;28:586-94.

[8] Clarke B, Kingshott P, Hou X, Rochev Y, Gorelov A, Carroll W. Effect of nitinol wire surface properties on albumin adsorption. Acta Biomaterialia. 2007;3:103-11.

[9] Shabalovskaya SA. Surface, corrosion and biocompatibility aspects of Nitinol as an implant material. Biomed Mater Eng. 2002;12:69109.

[10] Talha M, Ma Y, Kumar P, Lin Y, Singh A. Role of protein adsorption in the bio corrosion of metallic implants-A review. Colloids Surf B Biointerfaces. 2019;176:494-506.

[11] Barrett DG, Sileika TS, Messersmith PB. Molecular diversity in phenolic and polyphenolic precursors of tannin-inspired nanocoatings. Chem Commun (Camb). 2014;50:7265-8.

[12] Sileika TS, Barrett DG, Zhang R, Lau KHA, Messersmith PB. Colorless multifunctional coatings inspired by polyphenols found in tea, chocolate, and wine. Angew Chem Int Ed. 2013;52:10766-70.

[13] Omanovic S, Roscoe SG. Electrochemical studies of the adsorption behavior of bovine serum albumin on stainless steel. Langmuir. 1999; 15:8315-21.

[14] Li P, Li L, Wang W, Jin W, Liu X, Yeung KW, et al. Enhanced corrosion resistance and hemocompatibility of biomedical NiTi alloy by atmospheric-pressure plasma polymerized fluorine-rich coating. Appl Surf Sci. 2014;297:109-15.
[15] Roy RK, Choi HW, Yi JW, Moon M-W, Lee K-R, Han DK, et al. Hemocompatibility of surface-modified, silicon-incorporated, diamond-like carbon films. Biomater Acta. 2009;5:249-56.

[16] Porcayo-Palafox E, Carrera-Chavez S, Casolco S, PorcayoCalderon J, Salinas-Bravo V. Electrochemical Performance of TiBased Commercial Biomaterials. Adv Mater Sci Eng. 2019;2019.

[17] Gurappa I. Characterization of different materials for corrosion resistance under simulated body fluid conditions. Mater Charact. 2002;49:73-9.

[18] Karimi S, Nickchi T, Alfantazi A. Effects of bovine serum albumin on the corrosion behaviour of AISI $316 \mathrm{~L}, \mathrm{Co}-28 \mathrm{Cr}-6 \mathrm{Mo}$, and $\mathrm{Ti}-$ $6 \mathrm{Al}-4 \mathrm{~V}$ alloys in phosphate buffered saline solutions. Corros Sci. 2011;53:3262-72.

[19] Mohsen Q, Fadl-allah SA, El-Shenawy NS. Electrochemical impedance spectroscopy study of the adsorption behavior of bovine serum albumin at biomimetic calcium-phosphate coating. Int $\mathrm{J}$ Electrochem Sci. 2012;7:4510-27.

[20] Stansbury EE, Buchanan RA. Fundamentals of electrochemical corrosion: ASM international; 2000.

[21] Conti MC, Aquilina D, Paternoster C, Vella D, Sinagra E, Mantovani D, et al. Influence of cold rolling on in vitro cytotoxicity and electrochemical behaviour of an Fe-Mn-C biodegradable alloy in physiological solutions. Heliyon. 2018;4:e00926.

[22] De Oliveira HP, De Melo CP. Use of electrical impedance spectroscopy as a practical method of investigating the formation of aggregates in aqueous solutions of dyes and surfactants. J Phys Chem B. 2011;115:6903-8.

[23] MacDonald MA, Andreas HA. Impact of Electrochemical Impedance Spectroscopy Experimental Variables on Adsorbed Protein Films, as Illustrated by Bovine Serum Albumin. Electroanalysis. 2015;27:1944-51.

[24] MacDonald MA, Andreas HA. Method for equivalent circuit determination for electrochemical impedance spectroscopy data of protein adsorption on solid surfaces. Electrochim Acta. 2014;129:290-9.

[25] Banerjee PC, Woo RP, Grayson SM, Majumder A, Raman R. Influence of zeolite coating on the corrosion resistance of AZ91D magnesium alloy. Materials. 2014;7:6092-104.

[26] Amirudin A, Thieny D. Application of electrochemical impedance spectroscopy to study the degradation of polymer-coated metals. Prog Org Coat. 1995;26:1-28.

[27] Nicholson J. Evaluation of the anti-corrosion performance of water-borne ionomer coatings using AC impedance. Surf Coat Int. 1994;77:472-6. 
[28] Myland JC, Oldham KB. Uncompensated resistance. 1. The effect of cell geometry. Anal Chem. 2000;72:3972-80.

[29] Oldham KB, Stevens NP. Uncompensated resistance. 2. The effect of reference electrode nonideality. Anal Chem. 2000;72:3981-8.

[30] Elgrishi N, Rountree KJ, McCarthy BD, Rountree ES, Eisenhart TT, Dempsey JL. A practical beginner's guide to cyclic voltammetry. J Chem Educ. 2017;95:197-206.

[31] Chembath M, Balaraju J, Sujata M. In Vitro Corrosion Studies of Surface Modified NiTi Alloy for Biomedical Applications. Adv Biomater. 2014;2014.

[32] Hinton AJ. Determination of coating adhesion using electrochemical impedance spectroscopy. Solartron, Materials Test, Farnborough, Hampshire, UK Materials Test Products, version. $2001 ; 1$.

[33] Shabalovskaya SA, Rondelli GC, Undisz AL, Anderegg JW, Burleigh TD, Rettenmayr ME. The electrochemical characteristics of native Nitinol surfaces. Biomaterials. 2009;30:3662-71.

[34] Rondelli G, Vicentini B. Evaluation by electrochemical tests of the passive film stability of equiatomic Ni-Ti alloy also in presence of stress-induced martensite. J Biomed Mater Res. 2000;51:47-54.

[35] Wang Q, Zheng Y. The electrochemical behavior and surface analysis of Ti50Ni47. 2Co2. 8 alloy for orthodontic use. Dent Mater. 2008;24:1207-11.
[36] Moulton S, Barisci J, Bath A, Stella R, Wallace G. Studies of double layer capacitance and electron transfer at a gold electrode exposed to protein solutions. Electrochim Acta. 2004;49:4223-30.

[37] Templeton DM, Sunderman FW, Herber RF. Tentative reference values for nickel concentrations in human serum, plasma, blood, and urine: evaluation according to the TRACY protocol. Sci Total Environ. 1994;148:243-51.

[38] Hu T, Chu C, Xin Y, Wu S, Yeung KW, Chu PK. Corrosion products and mechanism on NiTi shape memory alloy in physiological environment. J Mater Res. 2010;25:350-8.

[39] Valenti LE, De Pauli CP, Giacomelli CE. The binding of Ni (II) ions to hexahistidine as a model system of the interaction between nickel and His-tagged proteins. J Inorg Biochem. 2006;100:192200.

[40] Papaderakis A, Tsiplakides D, Balomenou S, Sotiropoulos S. Electrochemical impedance studies of $\mathrm{IrO} 2$ catalysts for oxygen evolution. J Electroanal Chem. 2015;757:216-24.

[41] Fleischer C, Chatzitakis A, Norby T. Intrinsic photoelectrocatalytic activity in oriented, photonic TiO2 nanotubes. Mater Sci Semicond Process. 2018;88:186-91.

[42] Norde W, Lyklema J. Why proteins prefer interfaces. J Biomater Sci Polym Ed. 1991;2:183-202.

[43] Pegueroles Neyra M. Interactions between titanium surfaces and biological components: Universitat Politècnica de Catalunya; 2009. 